\title{
ASSESS THE ECONOMIC IMACT OF CLIMATE CHANGE ON WHEAT, BARLEY, MAIZE AND SUNFLOWER IN SOUTHEAST BULGARIA
}

\author{
P. Branzova* \\ Economic Research Institute at BAS, Sofia, Bulgaria
}

\begin{abstract}
The report studied the impact of the expected climate change in the period 2020-2050 on the yield of wheat, barley, maize and sunflower in southeastern planning region (Southeast region) of Bulgaria. Estimated economic impact of climate change on agriculture in the Southeast region. By stepwise regression analysis, predictors are defined and obtained regression relations for the average yield for each of the studied crops with climate model REMO and climate scenario A1B. Enter the evaluation of error forecast yields for each of the studied cultures and reporting its receipt of the final forecasts. Based on regression equations obtained an estimate for the change in the average yield of the studied crops. There are formed groups to change average yields of crops studied, the results are used as input data for economic assessment and analysis. On the basis of these groups was determined the optimal structure of production to Southeast region for the period 2020-2050. Determine the required amounts of fuel, fertilizers and agro-chemical equipment for the production of the studied crops in Southeast region for the period 2020-2050 due to climate changes.
\end{abstract}

Key words: economic impact, economic results, agriculture, climate change.

\section{INTRODUCTION}

Climate change will continue to have a major impact on the biophysical processes that underpin agricultural sector. This will lead to both positive and negative implications for individual regions.

The expected increase in the concentration of carbon dioxide in the atmosphere and increasing the frequency of extreme weather events, such as higher air temperatures and changes in rainfall patterns will affect the volume and quality in food production and the natural environment on which develops agriculture. Also, climate change will impact on the water balance of the Regions, on soils, disease and pests that will significantly change the face of farming and animal husbandry. In extreme cases, abandonment is expected on the ground, which will lead to a complete loss of its production characteristics (1).

Therefore agriculture and crop yields in particular are the main object of interest in scientific research on climate impacts. From an economic perspective it can be

\footnotetext{
*Correspondence to: Petia Branzova, Economic Research Institute at BAS, tel. +359889759968, emailpetia85@gmail.com, SofiaAksakov Str.3
}

expected that climate change will lead to uncertainty in agricultural production and a decline in production from the agricultural sector, which can increase the volatility of the economic situation as farmers in different regions and in national economies (2).

The purpose of the work is to assess the economic impact of climate change on the average yields of wheat, maize, barley and sunflower at Southeast region for the period 2020-2050.

To obtain a quantitative assessment of the impact of climate change on the yield of wheat, barley, maize and sunflower Southeast region used the method of regression analysis. This is a classic method and is still used to solve a number of tasks such as the issue here. Quantification will be obtained by the following algorithm:

- In the first step, for obtaining the regression relationships are formed two rows of dataweather anomalies and details of variation in the yields of the test cultures to the training sample, the period 1961-1988(3);

- On the second stage using the method of multiple regression to determine the odds of sought regression equations and statistical 
evaluation of the reliability of the connections;

- The third stage is a real evaluation of material error estimates obtained regression equations in control sample for the period 1992-2011. It is based on a comparison of the actual yields of wheat, barley and sunflowers in the Southeast region, with projected;

- On the fourth stage in the resulting regression equations and simulated by climate models meteorological data for the period 2020-2050 is an estimate of the variation in the yields of wheat, barley, maize and sunflower Southeast region to the average yield for the base period. The calculated variations in yields correct the error of the forecast. To obtain the forecast yields for each year of the study period to the variation for the year average yield is added to the base period.

For economic research predicted yields are grouped into five groups according to the frequency, which occur in the period 20202050 year and are presented in Table 1. The grouping is made by the method of expert assessment by Prof. Dr. Sc. G. Mihnev.

Table 1. Options for change in yields $d$ [t/ ha] for Southeast region for the period 2020-2050.

\begin{tabular}{|c|c|c|c|c|c|c|c|c|c|c|}
\hline & \multicolumn{2}{|c|}{ Group 1} & \multicolumn{2}{|l|}{ Group 2} & \multicolumn{2}{|l|}{ Group 3} & \multicolumn{2}{|l|}{ Group 4} & \multicolumn{2}{|l|}{ Group 5} \\
\hline & yields & $\begin{array}{l}\text { frequ } \\
\text { ency }\end{array}$ & yields & $\begin{array}{l}\text { freq } \\
\text { uen } \\
\text { cy } \\
\end{array}$ & yields & $\begin{array}{l}\text { frequ } \\
\text { ency }\end{array}$ & yields & $\begin{array}{l}\text { frequ } \\
\text { ency }\end{array}$ & Yields & $\begin{array}{l}\text { freque } \\
\text { ncy }\end{array}$ \\
\hline Wheat & $\mathrm{d} \leq 1.71$ & 4 & $1.71<\mathrm{d} \leq 1.88$ & 10 & $1.88<\mathrm{d} \leq 2.25$ & 11 & $2.86<\mathrm{d} \leq 3.99$ & 2 & $3.99<\mathrm{d} \leq 4.33$ & 3 \\
\hline Barley & $\mathrm{d} \leq 2.03$ & 5 & $2.03<\mathrm{d} \leq 2.44$ & 10 & $2.44<\mathrm{d} \leq 2.87$ & 6 & $2.87<\mathrm{d} \leq 3.14$ & 5 & $3.14<\mathrm{d} \leq 3.65$ & 4 \\
\hline Maize & $\mathrm{d} \leq 2.02$ & 8 & $2.02<\mathrm{d} \leq 2.75$ & 10 & $2.75<\mathrm{d} \leq 3.28$ & 5 & $3.28<\mathrm{d} \leq 3.68$ & 4 & $3.68<\mathrm{d} \leq 4.68$ & 3 \\
\hline Sunflower & $\mathrm{d} \leq 0.98$ & 3 & $0.98<\mathrm{d} \leq 1.14$ & 9 & $1.14<\mathrm{d} \leq 1.37$ & 5 & $1.37<\mathrm{d} \leq 1.59$ & 11 & $1.59<\mathrm{d} \leq 1.81$ & 2 \\
\hline $\begin{array}{l}\text { Average } \\
\text { rates }\end{array}$ & & 5 & & $\begin{array}{l}9.7 \\
5\end{array}$ & & 6.75 & & 5.5 & & 3 \\
\hline Probabilities & & 0.17 & & $\begin{array}{l}0.3 \\
3 \\
\end{array}$ & & 0.23 & & 0.18 & & 0.10 \\
\hline
\end{tabular}

\section{Models to determine the optimal structure and strategy of production.}

The economic impact of climate change on agriculture in the Southeast region was analyzed as determine the optimal structure of production.

For this purpose is chosen methodology by which the physical changes in the average yields of wheat, barley, maize and sunflower are transformed in value based on the following assumptions (4):

- excluding the impact of prices on agricultural production- used a constant price;

- all other cultures remain intact;

- the value of livestock production and other activities in the gross agricultural production remain constant;

- need and labor costs remain constant;

- the need and cost of fuel is saved on the base period;

- amount used and the costs of nitrogen, phosphorus, agro-chemical equipment is stored.

Determination of the optimal structure of production, taking into account climate change in agriculture in the Southeast region of the forecast period 2020-2050 year.

Has been developed comes to making a strategic management decisions in optimizing the production structure based on the projections of the change in the average yields of wheat, barley, maize and sunflower in the Southeast region due to climate change. A management decision in this case gives an optimal response to the optimal structure of production in the plant, which will provide:

- Contract to feed plants corn production;

- Implementation of the contracts with the mills for the production of wheat;

- implementation of the contracts with breweries in the production of barley;

- Contract to crushing plants for the production of sunflower;

- To answer about the number and structure of the permanently employed in the production process and the need for temporary help.

- Adjustment with at least additional costs to climate change.

To determine the optimal structure of production, using economical mathematical model and task (5). 
Economical mathematical model (EMM) and the problem of determining the optimal production structure from the impact of climate change in Southeast region for the forecast period 2020-2050 year.

The purpose of this model is to determine optimal structure of production in the area, balancing production with available resources, etc., taking into account the impact of climate change on agriculture.

Important parts of the modeling are restrictive conditions in which the production process takes place. In the model of economical mathematical task (EMT) for the purpose of this work included the following restrictions:

- Restriction on earth express condition that production can not have more value attributed to land and carry out the purpose set before it;

- Restriction on crop rotation- is the minimum and maximum area of the merged cultures of crop rotation area;

- Restriction modeling the balance between demand and availability of labor resources;

- Restriction for fuels used, agro-chemical equipment and fertilization with nitrogen and phosphorus.

The next step is formulated objective function of economy mathematical task. The objective function is one of the most important moments of modeling. The criterion chosen should reflect most accurately the reality of production. Most often as a criterion for optimal use economic indicators clean production or net income (6). For the purpose of this work is selected criteria clean production.

The formation of the target function is necessary to clarify the issue with the assessment of different groups unknown.

- assessments in the target crop function is called conditional net production per hectare, or the difference between total production and direct costs;

- assessments unknown modeling variations in yields;

- Unknown expressing labor force;

- Unknown expressing the necessary quantities of fuel, phosphorus, nitrogen and agro-chemical equipment.

A very important point in the drafting of the model information is to create the task. Used are ready developments of technological maps for wheat, barley, maize and sunflower, which include all activities by preparing the area for sowing of the crop to harvest. Careful preparation of the information used in the model is a guarantee to obtain real and practicable optimal solutions.

Given the research topic, namely the impact of climate change on the yield of wheat, barley, maize and sunflower Southeast region for the period 2020-2050 year based in projected yields up to work is drawn up "adaptive model".

Adaptation of agriculture includes events that are presented in adaptive EMM through a group of unknowns. These unknown gains meaning in the optimal solution of the problem only, provided that the proportions of the elements in the economic system have been violated by the new conditions. In our case, the impact of climate change in Southeast region for the period 20202050 year on the yield of wheat, barley, sunflower and maize.

Adaptive economical mathematical model includes all unknown to ordinary economical mathematical model plus the unknown for adaptation.

The system restrictions the adaptive EMM incorporates all restrictions listed in up to ordinary linear model. As noted in this job needs and costs of fuels, phosphorus, nitrogen, labor, cost of production and agro-technical equipment are constant (a base year).

Based on the five options on the impact of climate change on yields of wheat, barley, maize and sunflower Southeast region for the period 2020-2050 year were developed five EMT, the above described manner (Table 2). The purpose is to determine the outcome that best adapts taking the structure of production at the respective adaptation and affect other indicators (labor, fuel, equipment and agro-chemical fertilizer costs, value added, etc.).

On the basis of five groups to amend the average yields of wheat, barley, maize and sunflower, by production of economical mathematical model determined the optimal structure of production in the Southeast region. The expected value of the output of the studied crops for the period 20202050 year amounted to 983857625 leva and the necessary funds for labor, nitrogen, phosphorus, agro- chemistry equipment and fuels amount to 306249590 leva. On the other hand, under the most unfavorable structure of agriculture in the region, the expected value of the output of the studied crops for the period 2020-2050 year amounted to 406510699 leva and the necessary funds for labor, nitrogen, phosphorus, agrochemistry equipment and fuels amount to 614 302180 leva.

Defined amounts are possible to negotiate with feed mills, flour mills, breweries and crushing plants. It was concluded that two of the options for the projected structure of production in the 
region, the needs of feed will have to be provided by one of the other regions of Bulgaria. However, Southeast region will be able to cover the needs of some of the other areas if there is a drop in the production of barley, sunflowers or wheat.
The results obtained in solving EMT adaptation strategies of the economic system to climate change can be used to analyze the different strategies of the strategic decision.

Table 2. Results of economic-mathematical model in optimal production structure of the Southeast region characteristics and possible quantities negotiation.

\begin{tabular}{|c|c|c|c|c|c|}
\hline & \begin{tabular}{|l} 
Group 5, \\
adapt. 1
\end{tabular} & $\begin{array}{l}\text { group 5, adapt. } \\
2\end{array}$ & $\begin{array}{l}\text { group 5, adapt. } \\
\text { 3 }\end{array}$ & $\begin{array}{l}\text { Group 5, } \\
\text { adapt.4 }\end{array}$ & $\begin{array}{l}\text { Group 5, } \\
\text { adapt.5 }\end{array}$ \\
\hline & $\begin{array}{l}\text { Value of } \\
\text { production }\end{array}$ & $\begin{array}{l}\text { Value of } \\
\text { production }\end{array}$ & $\begin{array}{l}\text { Value of } \\
\text { production }\end{array}$ & $\begin{array}{l}\text { Value of } \\
\text { production }\end{array}$ & $\begin{array}{l}\text { Value of } \\
\text { production }\end{array}$ \\
\hline \begin{tabular}{|l|} 
Production \\
wheat \\
\end{tabular} & 233086715 & 212596715 & 174291140 & 323068446 & 334174741 \\
\hline $\begin{array}{l}\text { Production } \\
\text { barley }\end{array}$ & 189228395 & 205525737 & 198531138 & 80232308 & 71362881 \\
\hline $\begin{array}{l}\text { Production } \\
\text { maize }\end{array}$ & 0 & 0 & 425139395 & 439808187 & 458820235 \\
\hline $\begin{array}{l}\text { Production } \\
\text { sunflower }\end{array}$ & 401291568 & 401291568 & 101434514 & 89703804 & 74499769 \\
\hline Total & 823606679 & 819414020 & 899396186 & 932812744 & 938857625 \\
\hline Labor costs & 29760630 & 29744740 & 52021260 & 52891530 & 53880190 \\
\hline $\begin{array}{l}\text { Costs for } \\
\text { nitrogen }\end{array}$ & 31970430 & 31880660 & 33674210 & 34379330 & 31880660 \\
\hline $\begin{array}{l}\text { Costs for } \\
\text { phosphorus }\end{array}$ & 67863570 & 67606720 & 72738700 & 74756310 & 75119200 \\
\hline Fuels & 399529100 & 39851620 & 44737970 & 45624320 & 45885020 \\
\hline $\begin{array}{l}\text { Agro-chemistry } \\
\text { equipment }\end{array}$ & 85178450 & 84913650 & 96417610 & 98764510 & 99484520 \\
\hline All direct costs & 529123730 & 169083740 & 203172140 & 207651490 & 206765070 \\
\hline Value added & 294482949 & 650330280 & 696224046 & 725161254 & 732092555 \\
\hline \multicolumn{6}{|l|}{$\begin{array}{l}\text { Possible } \\
\text { quantities for } \\
\text { negotiation }\end{array}$} \\
\hline Wheat & 605420 & 552199 & 452704 & 839139 & 867986 \\
\hline Barley & 524178 & 569323 & 549948 & 222250 & 197681 \\
\hline Maize & 0 & 0 & 1167965 & 1208264 & 1260495 \\
\hline Sunflower & 538646 & 538646 & 136154 & 120408 & 100000 \\
\hline
\end{tabular}

\section{CONCLUSION}

The report estimated the economic impact of the expected climate change on Bulgarian agriculture in South-East planning Bulgaria (Southeast region). Based on the analyzes and resulting can conclude that the climatic changes in the Southeast region will lead to changes in the average yield of the studied crops for the forecast period 2020-2050 year, which in turn will influence the structure of the economy in the area.

\section{REFERENCE}

1. Alexandrov, V."Climate Change", sections 1 and 8, 2010
2. Mishev Plamen, Mochurova M., Climate change impacts on tourism, International conference "Global environmental change: challenges to Science and society in southeastern Europe", http://globalchange.meteo.bg/conference_en.htm, 19-21 May 2008, Sofia, Bulgaria.

3. Annuals NSI 1961-1999.

4. Agricultural Statistics MAF, 2012.

5. Asparuhova, I.(1999). Economic and mathematical modeling of agricultural production.

6. Avramov A. \& Grozev S. (1996). Fundamentals of mathematical modeling in economics. 